Article

\title{
Regional Total Factor Energy Efficiency Evaluation of China: The Perspective of Social Welfare
}

\author{
Haixia Cai ${ }^{1, *}$ and Ruguo Fan ${ }^{2}$ \\ 1 Systems and Industrial Engineering Technology Research Center, Zhongyuan University of Technology, \\ Zhengzhou 450007, China \\ 2 School of Economics and Management, Wuhan University, Wuhan 430072, China \\ * Correspondence: hx_cai@126.com; Tel.: +86-371-8607-7130
}

Received: 4 July 2019; Accepted: 26 July 2019; Published: 29 July 2019

check for updates

\begin{abstract}
The energy resource is an essential input of economic growth, which has an important impact on the ecological environment and social welfare. From the perspective of social welfare, considering the radial and non-radial characteristics of different input and output indicators, and the inseparability of the energy input and undesirable output, this study employs the non-separable hybrid DEA (Data Envelopment Analysis) model to evaluate the total energy efficiency of Chinese provinces between 2012 and 2016. Furthermore, this study calculates the energy saving and emission reduction potentials of China. The results reveal that the average total factor energy efficiency in China from 2012 to 2016 is 0.694 , which means that there are still $30.6 \%$ energy efficiency losses. There is great potential for China to save energy, reduce pollutant emissions, and increase the output of social welfare. There are great differences in the total factor energy efficiency among provinces. The average energy saving potential of the whole country is $60.5 \%$. If the energy efficiency of all provinces can reach the frontier, the whole country can save more than half of the energy consumption. The highest national average emission reduction potential is $\mathrm{SO}_{2}$, followed by dust, $\mathrm{CO}_{2}$, and $\mathrm{NO}_{\mathbf{X}}$. The implication of the conclusion is that in the development of regional economy, we cannot sacrifice the social welfare and sustainable development and take the growth rate of GDP as the only objective. Different energy saving and emission reduction policies should be put forward according to the characteristics of different provinces.
\end{abstract}

Keywords: social welfare; total factor energy efficiency; energy saving and emission reduction potential; non-separable hybrid DEA model

\section{Introduction}

The long-term preference for high-speed economic growth means that China is facing a serious energy shortage. In particular, the use of fossil energy has led to serious ecological and environmental problems, which restrict the improvement of the overall level of people's social welfare. Daley, an eco-economist, argues that ecological capital is the fundamental means of economic and social development, that the level of welfare or quality of life is the ultimate goal of economic and social development, and that economic growth assumes the function of intermediate means and objectives [1]. At present, China is in a critical period of the new normal economy and the construction of a moderately prosperous society in all respects. We should not only steadily promote economic growth, but also constantly improve people's social welfare, but not at the expense of the ecological environment. That is to say, to promote the coordinated and coupled development of economic, social, ecological, and natural resource systems by means of moderate economic growth and ultimately to maximize the social welfare, are major problems that China urgently needs to solve. 
Energy resources are the key factors promoting economic growth and social welfare. At the same time, the exhaust emissions generated in the process of energy consumption are the main cause of environmental pollution and global warming. International Energy Agency (IEA) [2] research shows that global energy-related carbon dioxide emissions increased by $1.6 \%$ in 2017, after three consecutive years of staying static. Carbon emissions will continue to grow in 2018, which is far from meeting the climate change targets. Since 2006, China has become the world's largest greenhouse gas emitter, facing enormous energy and environmental pressures. China's ecological construction and environmental governance have entered a critical period of overlapping pressures and are going forward with a heavy burden [3]. However, the severe challenge does not mean that China is unable to grasp the window period to solve the outstanding problems of the ecological environment. Moreover, relevant studies show that some countries and regions can gain higher social welfare with less environmental and energy costs [4].Therefore, in such a critical period, to fully understand the relationship between energy and people's welfare and to measure the regional total factor energy efficiency in China from the perspective of social welfare, we cannot only take into account the relationship between energy, the ecological environment, social development and economic growth, but must also further clarify the policy implications of the measurement results, and lay a solid technical foundation for the investigation of "energy conservation and emission reduction" and sustainable development.

Generally speaking, energy efficiency includes the partial factor energy efficiency and total factor energy efficiency (TFEE) [5]. The partial factor energy efficiency refers to the ratio of the effective output and energy input of an economy, while the total factor energy efficiency believes that energy efficiency is the result of the substitution and influence of various inputs. The basic ideas are as follows: first, the production possibility set (production technology) is defined; then, the frontier production boundary is constructed by using the input-output data of each production unit; finally, the relationship between each production unit and frontier production boundary is analyzed. If the production unit deviates from the frontier production boundary, the resources of the production unit have not been fully utilized and there is room for Pareto improvement [6].

At present, there are two main methods for calculating the total factor energy efficiency: the non-parametric data envelopment analysis (DEA) method and parameter Stochastic Frontier Approach (SFA) method. Compared with the SFA method, the DEA method does not need to set the production function and related parameters, and thus avoids errors caused by function setting errors. Especially in the calculation of energy efficiency, multiple desired and undesired outputs are usually considered, and the DEA method has great advantages in this respect, having become the mainstream method of total factor energy efficiency research [7]. According to Hu and Wang [5], the total factor energy efficiency for province $i$ at time $t$ can be defined as

$$
\operatorname{TFEE}(\mathrm{i}, \mathrm{t})=\frac{\text { Target Energy Input }(\mathrm{i}, \mathrm{t})}{\text { Actual Energy Input }(\mathrm{i}, \mathrm{t})}
$$

The energy input here mainly refers to primary fossil energy, including coal, oil, natural gas, and so on, but does not include non-combustible renewable energy, such as solar energy, wind energy, water energy, and so on. Because the energy consumption structure of China's provinces varies greatly, in order to unify the caliber, the total energy consumption of each province is generally calculated by using various reference coefficients of standard coal for energy conversion.

Most of the existing studies take the Gross Domestic Product (GDP) as the desired output, and $\mathrm{CO}_{2}$ (carbon dioxide) and $\mathrm{SO}_{2}$ (sulfur dioxide) emissions as the non-desired output, to measure the total factor energy efficiency at the regional, national, or industrial level [8-10]. However, in addition to the economic output, the desired output from energy consumption should include a series of social outputs, such as social welfare. GDP, as the only desired output, ignores the impact of energy consumption on social welfare; in addition, $\mathrm{SO}_{2}$ or $\mathrm{CO}_{2}$ can no longer represent the full impact of energy consumption on the environment. In fact, the main pollutants emitted in the process of energy consumption include $\mathrm{NO}_{x}$ (nitrogen oxides) and smoke (powder) dust. Therefore, this study focuses on the impact of energy 
consumption on real social progress and social welfare, and takes into account the major pollutants causing environmental pollution and haze weather in the undesired output, which include $\mathrm{SO}_{2}, \mathrm{CO}_{2}$, $\mathrm{NO}_{\mathrm{x}}$, and smoke (powder) dust.

The rest of the study is arranged as follows: Section 2 presents the literature review; Section 3 describes the research method; Section 4 describes the data and variable selection; Section 5 presents the energy efficiency results with a discussion; Section 6 analyzes the energy saving and emission reduction potential; and lastly, Section 7 presents conclusions and policy implications.

\section{Literature Review}

The energy resource is an essential input of economic growth, which has an important impact on the ecological environment and social welfare. On the premise of the fixed scale of energy consumption, improving the energy efficiency is the key approach to improve people's livelihood [11]. The measurement of energy efficiency has been one of the research hotspots in the field of energy economy for many years, which has produced a large number of high-level research results. On the whole, the measurement of energy efficiency has experienced evolution from "economic growth orientation" to "ecological environment orientation" to "sustainability orientation" (Figure 1).

\begin{tabular}{|c|c|c|c|}
\hline $\begin{array}{l}\text { economic growth } \\
\text { orientation }\end{array}$ & $\begin{array}{l}\text { ecological environment } \\
\text { orientation }\end{array}$ & & $\begin{array}{l}\text { sustainability } \\
\text { orientation }\end{array}$ \\
\hline $\begin{array}{l}\text { Output : } \\
\text { •Economic output } \\
\text { (GDP) }\end{array}$ & $\begin{array}{l}\text { Output : } \\
\text { •Economic output } \\
\text {-Environmental pc }\end{array}$ & $\begin{array}{l}\text { (GDP) } \\
\text { Ilution }\end{array}$ & $\begin{array}{l}\text { Output : } \\
\text {-Social welfare } \\
\text {-Environmental pollution }\end{array}$ \\
\hline
\end{tabular}

Figure 1. Total factor energy efficiency (TFEE) measurement orientation.

\subsection{Traditional Economic Growth Orientation}

Initial research results are oriented by economic growth. They mainly consider capital, labor, and energy as inputs, and GDP as the output, and use the DEA model and traditional productivity index (Malmquist productivity index) to measure the total factor energy efficiency [5]. Under the orientation of economic growth, people are mainly concerned about the contribution of energy consumption to GDP growth. However, there are many problems in the GDP calculation itself. For example, GDP growth does not take into account the undesired output of energy consumption, such as carbon dioxide and sulfur dioxide, and the quality of ecosystems, nor does it take into account people's feelings about happiness. Such orientation conveys the wrong message to policymakers. With the deterioration of the ecological environment, researchers and policy makers believe that the impact of energy consumption on the ecological environment should be considered in the measurement of energy efficiency.

\subsection{Ecological Environment Orientation}

Scheel (2001) believes that the actual production process will inevitably produce undesired outputs, such as $\mathrm{CO}_{2}$. Therefore, it is necessary to consider the undesired outputs in the traditional model [12]. For the first time, Zhou and Ang considered the undesired output in energy efficiency evaluation, and developed the DEA model based on environmental DEA technology to evaluate the energy efficiency [13]. Since then, more and more scholars have adopted the eco-TFEE model, including desired and undesired outputs, in the evaluation of energy efficiency. Shen Neng and Wang Qunwei used the pollution emission index as a non-consensual output to measure China's regional energy efficiency [14]. Nicholas Apergis et al. estimated the energy efficiency of OECD (Organization for Economic Co-operation and Development) countries using the undesirable output DEA model based on slack variables [15]. Wang Bing et al. took the regional GRP (Gross Regional Product) as the desired output, regional $\mathrm{CO}_{2}$ emissions as the undesired output, and labor capital and energy as the input, 
and used the four-stage SBM model to measure the total factor energy efficiency, carbon emission efficiency, and natural effects of 30 provinces in China from 2000 to 2010. On this basis, the theoretical and actual energy saving and emission reduction potential were analyzed [16]. Wang Tingting and Zhu Jianping constructed the DEA ecological total factor energy efficiency model with the undesired output, and applied the model to carry out empirical analysis and discussion on the coordinated development of energy consumption and the environment in China's inter-provincial power industry [17].

It is possible to overestimatethe energy efficiency by considering a single desired output and ignoring the undesired outputs, such as environmental pollution and carbon emissions. This has been confirmed by relevant studies. $\mathrm{Li}$ and $\mathrm{Hu}$ used the SBM model to evaluate the regional total factor energy efficiency of China, and considered the impact of the undesired output. The conclusion is that the total factor energy efficiency is lower than that of energy efficiency without considering the undesired output [18]. Li Lanbing considers that ignoring the existence ofthe undesired output will lead to an overestimation of China's total factor energy efficiency. This is mainly due to the overestimation of the rate of technological progress in energy use. Under the emission reduction constraints, the rate of technological progress in energy use has decreased compared with only considering the dimension of energy conservation. To some extent, the level of technological progress in emission reduction is lower than the level of technological progress in energy conservation [19].

\subsection{Sustainability Orientation}

The traditional estimation of energy efficiency under the orientation of economic growth considers that the final output of production factors, such as labor, capital, and energy, is single, which is generally considered to be the growth of GDP. In the existing literature, most scholars are still confined to the traditional neoclassical economic paradigm and regard economic output as an alternative variable to social welfare. However, the reality is that more wealth does not necessarily lead to greater happiness, which is the so-called "Easterlin paradox". Liao Hua and Wei Yiming regard energy efficiency as a systematic and dynamic concept closely related to the economy, society, environment, and technology. Its connotation is "the contribution of energy consumption to maintaining or promoting the sustainable development of the whole economic, social and environmental system" [20]. In this case, more energy efficiency researchers turn to sustainability orientation and pay more attention to the impact of energy consumption and energy efficiency improvement on social welfare. Mazur examined the relationship between energy consumption per capita and quality of life in 21 developed countries from 1980 to 2006, and found that the increase in energy consumption did not lead to the same improvement in quality of life [21]. Sweidan and Alwaked found that there was a positive correlation between economic development and energy welfare intensity through the study of the Gulf Cooperation Council for Arab States from 1995 to 2012 [22]. Angeliki N. and Cant. studied the causal relationship between energy consumption and sustainable economic well-being growth in G7 countries. In this study, they constructed an Index of Sustainable Economic Welfare (ISEW), emphasizing the impact of energy consumption and conservation on improving people's quality of life and welfare. The study found that in the long run, G7 countries can reduce energy consumption without reducing sustainable welfare [23]. Further studies by Angeliki N. and Antonio C. point out that sustainable economic welfare indicators should be used as the output instead of traditional GDP indicators when analyzing the relationship between energy and economy [24].

From the orientation evolution of the above energy efficiency measurement, the development goal or welfare component is not limited to economic growth, but covers the connotation of economic, social, and environmental multi-dimensional welfare. Ignoring social welfare would be contrary to the goal of sustainable socio-economic development. Traditionally, the main purpose of energy consumption is to promote GDP growth. However, GDP estimation does not distinguish the activities of increasing and reducing welfare, and cannot reflect real social progress and welfare. Therefore, energy efficiency policymakers and designers have turned their attention to the role of energy saving in real social progress and welfare. However, the research on energy efficiency by combining energy 
and social welfare is only just emerging. The existing research only includes a simple measure of single factor energy welfare performance indicators or energy welfare intensity indicators. Little attention has been paid to the complex relationship between social welfare, energy, the environment, and economic growth. Additionally, the research object has mainly been considered at national and international levels, and little attention has been paid to empirical study at a provincial level in China.

Accordingly, this paper attempts to expand the existing literature from the following two aspects: (1) considering the impact of energy consumption on social welfare, taking social welfare as the desired output instead of GDP indicators; (2) using a non-separable Hybrid DEA model of the undesired output, considering the radial and non-radial characteristics of different input and output indicators, evaluating the regional total factor energy efficiency from the perspective of social welfare, and calculating the energy-saving and emission reduction potential of provinces. Based on this, the countermeasures and suggestions for improving the effect of energy welfare will be put forward. This can take into account the relationship between energy, the environment, social welfare, and economic growth, and clarify the policy implications of the measurement results, laying a solid technical foundation for investigating the issues of "energy conservation and emission reduction", "energy and social welfare", and sustainable development.

\section{Research Method}

Since Charnes and Cooper [25] put forward the first DEA model in 1978, the DEA method has become one of the commonly used methods in the field of productivity measurement after many people's efforts. Especially with the rise of energy and environment issues, the DEA method has been widely used in energy and environment efficiency measurement, which has produced a large number of fruitful results. Toner [26] proposed a non-separable hybrid DEA model to measure the overall efficiency of U.S. electric utilities. This model considers radial and non-radial inputs and outputs and addresses non-separable desirable and undesirable outputs. This paper applies this non-separable hybrid DEA model to calculate the regional total factor energy efficiency from the perspective of social welfare. The model can deal with a variety of undesired outputs, taking into account the inseparability between the energy input and output. The model can be described as follows:

The input and output data set matrices $X \in R^{m \times n}$ and $Y \in R^{s \times n}$ are decomposed as follows:

$$
X=\left(\begin{array}{c}
X^{S} \\
X^{N S}
\end{array}\right), Y=\left(\begin{array}{c}
Y^{S G} \\
Y^{S B} \\
Y^{N S G} \\
Y^{N S B}
\end{array}\right)
$$

where $\mathrm{n}$ represents $\mathrm{n}$ similar decision-making units (DMUs) in the production system, and $\mathrm{m}$ and $s$ represent the input and output indicators of DMUs, respectively. $X^{S} \in R^{m 1 \times n}$ and $X^{N S} \in R^{m 2 \times n}$ represent the separable and non-separable input data matrices, respectively. $m=m 1+m 2 . Y^{S G} \in R^{s 1 \times n}$, $\mathrm{Y}^{\mathrm{SB}} \in \mathrm{R}^{\mathrm{s} 2 \times \mathrm{n}}, \mathrm{Y}^{\mathrm{NSG}} \in \mathrm{R}^{\mathrm{s} \times \mathrm{n}}$, and $\mathrm{Y}^{\mathrm{NSB}} \in \mathrm{R}^{\mathrm{s} 4 \times \mathrm{n}}$ denote the separable desired output, separable undesired output, non-separable desired output, and non-separable undesired output. $s=s 1+s 2+s 3+s 4$. Then, the set of production possibilities can be defined as

$$
P_{N S}=\left\{\left(x^{S}, x^{N S}, y^{S G}, y^{S B}, y^{N S G}, y^{N S B}\right) \mid x^{S} \geq X^{S} \lambda, x^{N S} \geq X^{N S} \lambda, y^{S G} \leq Y^{S G} \lambda, y^{S B} \geq Y^{S B} \lambda, y^{N S G} \leq Y^{N S G} \lambda, y^{N S B} \geq Y^{N S B} \lambda\right\}
$$

where $\lambda$ is the weight vector.

The production possibility set has the following characteristics:

(1) Non-separable inputs and outputs are radial, and they are linked via the reduction rate variable $\theta$ $(0 \leq \theta \leq 1)$

(2) Separable inputs and outputs are non-radial; 
(3) While the non-separable undesired output decreases, the non-separable desired output decreases proportionally.

$\mathrm{A} \mathrm{DMU}_{\mathrm{o}}\left(\mathrm{x}_{\mathrm{o}}^{\mathrm{S}}, \mathrm{x}_{\mathrm{o}}^{\mathrm{NS}}, \mathrm{y}_{\mathrm{o}}^{\mathrm{SG}}, \mathrm{y}_{\mathrm{o}}^{\mathrm{SB}}, \mathrm{y}_{\mathrm{o}}^{\mathrm{NSG}}, \mathrm{y}_{\mathrm{o}}^{\mathrm{NSB}}\right)$ is NS-efficient if and only if, for any $\theta(0 \leq \theta \leq 1)$, one has $\left(x_{\mathrm{o}}^{\mathrm{S}}, \theta \mathrm{x}_{\mathrm{o}}^{\mathrm{NS}}, \mathrm{y}_{\mathrm{o}}^{\mathrm{SG}}, \mathrm{y}_{\mathrm{o}}^{\mathrm{SB}}, \theta \mathrm{y}_{\mathrm{o}}^{\mathrm{NSG}}, \theta \mathrm{y}_{\mathrm{o}}^{\mathrm{NSB}}\right) \notin \mathrm{P}_{\mathrm{NS}}$ and there is no $\left(\mathrm{x}^{\mathrm{S}}, \mathrm{x}^{\mathrm{NS}}, \mathrm{y}^{\mathrm{SG}}, \mathrm{y}^{\mathrm{SB}}, \mathrm{y}^{\mathrm{NSG}}, \mathrm{y}^{\mathrm{NSB}}\right) \in \mathrm{P}_{\mathrm{NS}}$, such that $x_{\mathrm{o}}^{\mathrm{S}} \geq \mathrm{x}^{\mathrm{S}}, \mathrm{y}_{\mathrm{o}}^{\mathrm{SG}} \leq \mathrm{y}^{\mathrm{SG}}, \mathrm{y}_{\mathrm{o}}^{\mathrm{SB}} \geq \mathrm{y}^{\mathrm{SB}}, \mathrm{x}_{\mathrm{o}}^{\mathrm{NS}} \geq \mathrm{x}^{\mathrm{NS}}, \mathrm{y}_{\mathrm{o}}^{\mathrm{NSG}} \leq \mathrm{y}^{\mathrm{NSG}}$, and $\mathrm{y}_{\mathrm{o}}^{\mathrm{NSB}} \geq \mathrm{y}^{\mathrm{NSB}}$, with at least one strict inequality with these inequalities. Then, the non-separable hybrid energy efficiencyvalue can be defined as

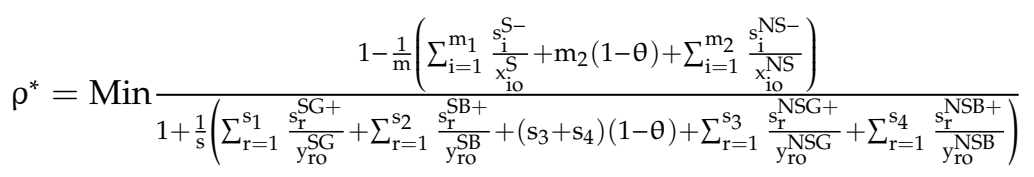

$$
\begin{aligned}
& \text { s.t. }\left\{\begin{array}{c}
\mathrm{x}_{\mathrm{o}}^{\mathrm{S}}=\mathrm{X}^{\mathrm{S}} \lambda+\mathrm{s}^{\mathrm{S}-} \\
\theta \mathrm{x}_{\mathrm{o}}^{\mathrm{NS}}=\mathrm{X}^{\mathrm{NS}} \lambda+\mathrm{s}^{\mathrm{NS}-} \\
\mathrm{y}_{\mathrm{o}}^{\mathrm{SG}}=\mathrm{Y}^{\mathrm{SG}} \lambda-\mathrm{s}^{\mathrm{SG}+} \\
\mathrm{y}_{\mathrm{O}}^{\mathrm{SB}}=\mathrm{Y}^{\mathrm{SB}} \lambda+\mathrm{s}^{\mathrm{SB}+} \\
\theta \mathrm{y}_{\mathrm{O}}^{\mathrm{NSG}}=\mathrm{Y}^{\mathrm{NSG}} \lambda-\mathrm{s}^{\mathrm{NSG}+} \\
\theta \mathrm{y}_{\mathrm{O}}^{\mathrm{NSB}}=\mathrm{Y}^{\mathrm{NSB}} \lambda+\mathrm{s}^{\mathrm{NSB}+} \\
\mathrm{s}^{\mathrm{S}-} \geq 0, \mathrm{~s}^{\mathrm{NS}-} \geq 0, \mathrm{~s}^{\mathrm{SG}+} \geq 0, \mathrm{~s}^{\mathrm{SB}+} \geq 0, \mathrm{~s}^{\mathrm{NSG}+} \geq 0, \mathrm{~s}^{\mathrm{NSB}+} \geq 0 \\
\mathrm{y}_{\mathrm{r}}^{\mathrm{SG}} \leq(1+\delta) \mathrm{y}_{\mathrm{ro}}^{\mathrm{SG}}(r=1, \cdots, \mathrm{s} 1) \\
\lambda \geq 0,0 \leq \theta \leq 1 \\
\mathrm{~m}=\mathrm{m} 1+\mathrm{m} 2, \mathrm{~s}=\mathrm{s} 1+\mathrm{s} 2+\mathrm{s} 3+\mathrm{s} 4
\end{array}\right.
\end{aligned}
$$

where $\mathrm{s}^{\mathrm{S}-}, \mathrm{s}^{\mathrm{NS}-}, \mathrm{s}^{\mathrm{SG}+}, \mathrm{s}^{\mathrm{SB}+}, \mathrm{s}^{\mathrm{NSG}+}$, and $\mathrm{s}^{\mathrm{NSB}+}$ are slacks to respective inputs or outputs. $\delta$ is an expansion ratio of the separable desired outputs. It is worth noting that the undesired outputs are proportional to the desired outputs. A decrease of the undesired output is accompanied by a decrease of the desired output. Therefore, the total desired output will decrease if the separable desired output does not increase. To solve this problem, we need to add a constraint condition to the model, that is, the total output amount remains at the current level as follows:

$$
\sum_{\mathrm{r}=1}^{\mathrm{s}_{1}} \mathrm{y}_{\mathrm{r}}^{\mathrm{SG}}+\sum_{\mathrm{r}=1}^{\mathrm{s}_{3}} \mathrm{y}_{\mathrm{r}}^{\mathrm{NSG}}=\sum_{\mathrm{r}=1}^{\mathrm{s}_{1}} \mathrm{y}_{\mathrm{ro}}^{\mathrm{SG}_{\mathrm{r}}}+\sum_{\mathrm{r}=1}^{\mathrm{s}_{3}} \mathrm{y}_{\mathrm{ro}}^{\mathrm{NSG}}
$$

The $\mathrm{DMU}_{\mathrm{o}}$ is in the production frontier and efficient if and only if $\rho^{*}=1$; if $0 \leq \rho^{*}<1$, then the $\mathrm{DMU}_{\mathrm{o}}$ is inefficient and can be improved.

\section{Data and Variable Selection}

Using panel data of 30 provinces in China from 2012 to 2016, this paper chooses capital stock, labor force, and energy consumption as the input variables. In terms of the output variables, most existing studies regard GDP as the desired output and $\mathrm{SO}_{2}$ or $\mathrm{CO}_{2}$ as the undesired output. The limitations of this approach lie in the fact that, firstly, the desired outputs of energy consumption should not be limited to GDP growth, and social welfare should be considered. Secondly, $\mathrm{SO}_{2}$ or $\mathrm{CO}_{2}$ can no longer represent the full impact of energy consumption on the environment. In fact, the main pollutants emitted in the process of energy consumption also include $\mathrm{NO}_{\mathrm{x}}$ (nitrogen oxides) and smoke (powder) dust. In 2010, the total emission of $\mathrm{NO}_{\mathrm{x}}$ in China exceeded $\mathrm{SO}_{2}$ and became one of the major air pollutants [27]. Especially when dealing with PM2.5 heavy pollution in winter, if thee mission of $\mathrm{NO}_{\mathrm{x}}$ can be reduced to a greater extent, the pollution treatment effect may be more obvious (He Kebin, 2017) [28]. The selection of input and output variables is shown in Table 1. 
Table 1. Variables.

\begin{tabular}{|c|c|c|}
\hline Variables & Type of Inputs and Outputs & Data Explanation \\
\hline Capital stock & Separable input & $\begin{array}{l}\text { The capital stock of China's provinces is estimated by the } \\
\text { method of Perpetual inventory. }\end{array}$ \\
\hline Labor & Separable input & $\begin{array}{l}\text { The number of employees in each province over the } \\
\text { years is used as labor input. }\end{array}$ \\
\hline $\begin{array}{l}\text { Energy } \\
\text { consumption }\end{array}$ & Non-separable input & $\begin{array}{l}\text { The total energy consumption of each province is used as } \\
\text { energy input. }\end{array}$ \\
\hline HDI & Separable desired output & $\begin{array}{l}\text { Human Development Index (HDI) is used to represent } \\
\text { social welfare level as desired output. }\end{array}$ \\
\hline $\begin{array}{c}\mathrm{CO}_{2}, \mathrm{SO}_{2} \\
\mathrm{NO}_{\mathrm{x}}, \text { smoke } \\
\text { (powder) dust }\end{array}$ & $\begin{array}{c}\text { Non-separable undesired } \\
\text { output }\end{array}$ & $\begin{array}{l}\text { The calculation of } \mathrm{CO}_{2} \text { is based on the classification of } \\
\text { China Energy Statistics Yearbook. The fossil energy } \\
\text { consumption can be divided into eight categories: coal, } \\
\text { coke, crude oil, gasoline, diesel, kerosene, fuel oil, and } \\
\text { natural gas. }\end{array}$ \\
\hline
\end{tabular}

The specific treatment of input-output variables is as follows:

\section{(1) Capital input}

This paper estimates the capital stock of China's provinces by using Zhang Jun's (2004) [29] sustainable inventory method. In order to eliminate the influence of the time factor, the annual capital stock is converted into the constant price in 1978 by using the GDP deflation index, as follows:

$$
\mathrm{K}_{\mathrm{i}(\mathrm{t}+1)}=\left(1-\delta_{\mathrm{it}}\right) \mathrm{K}_{\mathrm{it}}+\mathrm{I}_{\mathrm{i}(\mathrm{t}+1)}
$$

where $i$ represents the province $i$; $t$ represents the $t$ year, $K_{i(t+1)}$ and $K_{i t}$ denote the physical capital stock in $\mathrm{t}+1$ and $\mathrm{t}$ year, respectively; $\delta_{i t}$ refers to the depreciation rate of the physical capital stock in the $t$ year of the $i$ province; and $I_{i(t+1)}$ refers to the investment amount in $t+1$ year of $i$ province. Since the annual depreciation data of fixed assets in different regions can be given by the depreciation amount under the item of the Gross Domestic Product Income method in the China Statistical Yearbook, the formula for calculating the physical capital stock of each province and region is changed into

$$
\mathrm{K}_{\mathrm{i}(\mathrm{t}+1)}=\mathrm{K}_{\mathrm{it}}+\mathrm{I}_{\mathrm{i}(\mathrm{t}+1)}-\mathrm{D}_{\mathrm{i}(\mathrm{t}+1)}
$$

In Formula (7), $D_{i(t+1)}$ is the depreciation of fixed assets of $i$ province in $t+1$ year. According to Formula (7), we can get the capital stock of 30 provinces in China from 2012 to 2016.

(2) Labor input

The number of employees in each province over the years is used as the labor input.

(3) Energy input

The total energy consumption of each province is used as the energy input.

(4) Desired output

This paper takes the social welfare as the desired output. There is no unified conclusion on the measurement of social welfare. Because of the availability of data, scholars usually use the Human Development Index (HDI) developed by the United Nations Development Programme (UNDP) to represent the level of social welfare. HDI, as an effective measure of the human development level or social welfare, has been widely recognized and widely used (UNDP, 2015) [30]. In this paper, we use the latest HDI calculation method of UNDP, which includes the life expectancy index (LEI), education index (EI), and income index (II). The specific calculation methods are as follows:

$$
\mathrm{HDI}=\sqrt[3]{\mathrm{LEI} \times \mathrm{EI} \times \mathrm{II}}
$$


where,

$$
\text { LEI }=\frac{\text { Average life expectancy }-20}{83.4-20}
$$

Since China only has the census data of 1990, 2000, and 2010 and the1\% sample survey data of the population every five years, the average life expectancy data of the remaining years are replaced by the average life expectancy index of the nearest year; that is, the average life expectancy of the population in 2012-2013 and 2015-2016 is replaced by the data of 2010 and 2014, respectively.

The education index (EI) is composed of the average education index (AEI) and the expected education index (EEI). The specific calculation methods are as follows:

$$
\text { Average years of education }(\mathrm{AE})=\frac{6 \times P_{\text {prischool }}+9 \times P_{\text {juniorschool }}+12 \times P_{\text {highschool }}+16 \times P_{\text {college }}}{P_{\text {prischool }}+P_{\text {juniorschool }}+P_{\text {highschool }}+P_{\text {college }}}
$$

Expected years of education $(\mathrm{EE})=\sum_{i=1}^{4} W_{i} \times$ Gross enrollment rate of education at all levels

$$
\begin{aligned}
& \text { Average education index }(\mathrm{AEI})=\frac{A E-0}{13.1-0} \\
& \text { Expected education index }(\mathrm{EEI})=\frac{E E-0}{18-0}
\end{aligned}
$$

where, $P$ represents the population size of each academic education, $W$ represents the weight, $W_{1}=6$, $W_{2}=3, W_{3}=3$, and $W_{4}=4$. Then,

$$
\text { Education index }(\mathrm{EI})=\frac{\sqrt{A E I \times E E I}-0}{0.978-0}
$$

The income index (II) is calculated by the annual GDP per capita of each region, in which the per capita GDP is treated at the same price in 2012.

$$
\text { Income index }(\mathrm{II})=\frac{\ln (\text { GDP per capita })-\ln (100)}{\ln (75000)-\ln (100)}
$$

\section{(5) Undesired output}

Undesired outputs include $\mathrm{SO}_{2}, \mathrm{CO}_{2}, \mathrm{NO}_{\mathrm{x}}$, and smoke (powder) dust. According to the classification method of the China Energy Statistics Yearbook, the calculation of $\mathrm{CO}_{2}$ divides fossil energy consumption into eight categories: coal, coke, crude oil, gasoline, diesel, kerosene, fuel oil, and natural gas. Carbon emissions from all fossil fuels can be estimated based on the amount of fuels burned and the carbon emission factor [31].The formulas employed for calculating $\mathrm{CO}_{2}$ emissions from fossil fuel consumption are as follows: emissions = fossil fuel consumption $\times \mathrm{CO}_{2}$ emission coefficient and $\mathrm{CO}_{2}$ emission coefficient $=$ low calorific value $\times$ carbon oxidation rate $\times$ carbon content. The calculation results are shown in Table 2.

All the original data werederived fromthe China Statistical Yearbook, Human Development Report, China Environmental Statistical Yearbook, China Energy Statistical Yearbook, New China Statistical Data Compilation for 60 Years, provincial statistical yearbooks, and National Statistical Bureau website system data. 
Table 2. Emission coefficients of different energy sources.

\begin{tabular}{|c|c|c|c|c|}
\hline Energy Source & $\begin{array}{l}\text { Low Calorific } \\
\text { Value }(\mathbf{k J} / \mathbf{k g})\end{array}$ & $\begin{array}{c}\text { Carbon Content } \\
(\mathrm{kgC} / \mathrm{GJ})\end{array}$ & Oxidation Rate & $\begin{array}{l}\text { Carbon Emission } \\
\text { Coefficient }(\mathrm{tC} / \mathrm{t})\end{array}$ \\
\hline coal & 20,908 & 25.8 & 1 & 0.5394 \\
\hline coke & 28,435 & 29.2 & 1 & 0.8303 \\
\hline crude oil & 41,816 & 20.0 & 1 & 0.8363 \\
\hline gasoline & 43,070 & 18.9 & 1 & 0.8140 \\
\hline diesel & 42,652 & 20.2 & 1 & 0.8616 \\
\hline kerosene & 43,070 & 19.5 & 1 & 0.8399 \\
\hline fuel oil & 41,816 & 21.1 & 1 & 0.8823 \\
\hline natural gas & 38,931 & 15.3 & 1 & 0.4478 \\
\hline
\end{tabular}

Note: Thelow calorific value of natural gas is $\mathrm{kJ} / \mathrm{m}^{3}$.

\section{Empirical Analysis of Regional Total Factor Energy Efficiency}

Based on the input and output data from 2012 to 2016, the study used MAXDEA7.0 software to solve the non-separable hybrid DEA model, and obtained the total factor energy efficiency value considering the social welfare in China's provinces. The results are shown in Table 3.

Table 3. Efficiency values of provinces in China from 2012 to 2016.

\begin{tabular}{|c|c|c|c|c|c|c|}
\hline Province & 2012 & 2013 & 2014 & 2015 & 2016 & Average Value \\
\hline BEIJING & 1 & 0.990 & 1 & 0.898 & 1 & 0.978 \\
\hline TIANJIN & 1 & 0.907 & 0.906 & 0.875 & 1 & 0.938 \\
\hline HEBEI & 0.570 & 0.570 & 0.571 & 0.572 & 0.573 & 0.571 \\
\hline SHANXI & 0.574 & 0.574 & 0.574 & 0.575 & 0.580 & 0.575 \\
\hline INNER MONGOLIA & 0.575 & 0.575 & 0.575 & 0.576 & 0.584 & 0.577 \\
\hline LIAONING & 0.578 & 0.580 & 0.580 & 0.581 & 0.586 & 0.581 \\
\hline JILIN & 0.610 & 0.613 & 0.614 & 0.618 & 0.628 & 0.616 \\
\hline HEILONGJIANG & 0.593 & 0.596 & 0.595 & 0.596 & 0.598 & 0.595 \\
\hline SHANGHAI & 0.658 & 0.669 & 0.642 & 0.642 & 0.733 & 0.669 \\
\hline JIANGSU & 0.576 & 0.576 & 0.576 & 0.577 & 0.577 & 0.576 \\
\hline ZHEJIANG & 0.593 & 0.595 & 0.595 & 0.595 & 0.609 & 0.597 \\
\hline ANHUI & 0.602 & 0.593 & 0.592 & 0.592 & 0.621 & 0.600 \\
\hline FUJIAN & 0.616 & 0.620 & 0.614 & 0.618 & 0.629 & 0.619 \\
\hline JIANGXI & 0.630 & 0.624 & 0.622 & 0.619 & 0.624 & 0.624 \\
\hline SHANDONG & 0.568 & 0.569 & 0.568 & 0.568 & 0.570 & 0.569 \\
\hline HENAN & 0.581 & 0.577 & 0.577 & 0.577 & 0.589 & 0.580 \\
\hline HUBEI & 0.592 & 0.598 & 0.598 & 0.600 & 0.604 & 0.599 \\
\hline HUNAN & 0.599 & 0.601 & 0.603 & 0.603 & 0.605 & 0.602 \\
\hline GUANGDONG & 0.581 & 0.581 & 0.581 & 0.582 & 0.583 & 0.582 \\
\hline GUANGXI & 0.660 & 0.641 & 0.620 & 0.628 & 0.659 & 0.641 \\
\hline HAINAN & 1 & 1 & 0.961 & 0.947 & 1 & 0.982 \\
\hline CHONGQING & 0.646 & 0.669 & 0.661 & 0.661 & 0.673 & 0.662 \\
\hline SICHUAN & 0.632 & 0.612 & 0.604 & 0.605 & 0.635 & 0.618 \\
\hline GUIZHOU & 1 & 0.819 & 0.814 & 0.907 & 1 & 0.908 \\
\hline YUNNAN & 1 & 0.839 & 1.000 & 0.981 & 1 & 0.964 \\
\hline SHAN'XI & 0.588 & 0.588 & 0.587 & 0.589 & 0.600 & 0.591 \\
\hline GANSU & 0.944 & 0.812 & 0.713 & 0.753 & 1 & 0.845 \\
\hline QINGHAI & 1 & 1 & 0.993 & 1 & 1 & 0.999 \\
\hline NINGXIA & 1 & 1 & 0.867 & 0.922 & 1 & 0.958 \\
\hline XINJIANG & 0.593 & 0.588 & 0.586 & 0.589 & 0.605 & 0.592 \\
\hline whole country & 0.705 & 0.686 & 0.680 & 0.682 & 0.715 & 0.694 \\
\hline
\end{tabular}

\subsection{Overall Efficiency Scores in China from 2012 to 2016}

As a whole, the average total factor energy efficiency of China in 2012-2016 was0.694, which means that there is still $30.6 \%$ energy efficiency loss, saving energy consumption, reducing pollutant emissions, 
and increasing the output of social welfare. From the evolution trend (as shown in Figure 2), during the period 2012 to 2016, the overall energy efficiency scores of China showed a trend of first decreasing and then rising. Before 2014, the overall efficiency of China showed a significant decline, and reached the lowest score of 0.68 in 2014 . Afterwards, the energy efficiency began to pick up at a steady rate and reached the highest value of 0.715 in 2016. In 2016, eight provinces reached the frontier of energy efficiency, which was significantly higher than in previous years.

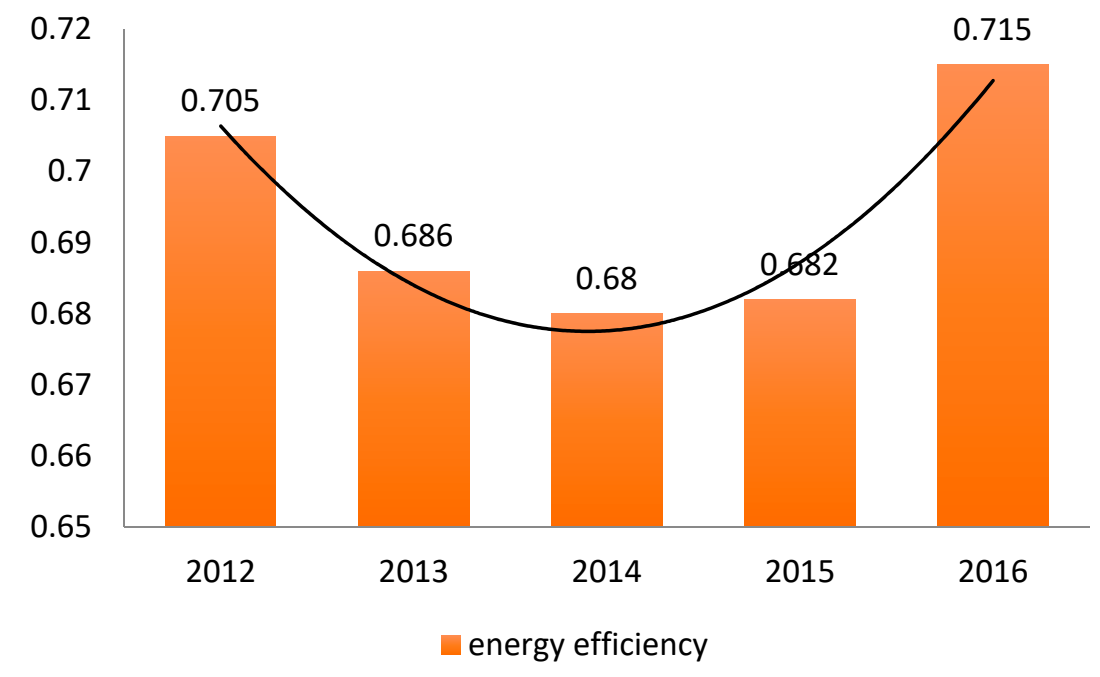

Figure 2. Efficiency scores in China from 2012 to 2016.

This is consistent with our intuitive feeling. 2013 and 2014 are the two years with the most serious air pollution in China. Frequent heavy fog and haze weather has greatly affected people's production, life, and health, thus harming people's welfare. Since then, the state has intensified efforts to control air pollution, and has issued a series of policies to reduce pollution emissions. After the 18th National Congress, China actively promoted the construction of ecological civilization, and proposed that a good ecological environment should be regarded as the most equitable and inclusive welfare of the people. In September 2013, the Action Plan for the Prevention and Control of Air Pollution was promulgated, and the goal of gradually reducing heavily polluted weather and improving air quality was put forward. Subsequently, various provinces have formulated and carried out a series of air pollution prevention and control action plans. The top-down attention to air pollution means that energy efficiency is gradually rising. 2016 was the third year of the implementation of the Action Plan for the Prevention and Control of air pollution, and the average energy efficiency of the whole country was greatly improved, which shows that the national control of air pollution is fruitful.

\subsection{Energy Efficiency in each Province from 2012 to 2016}

For each province, the total factor energy efficiency varies greatly (as shown in Figure 3). The provinces with the highest energy efficiency are Hainan and Qinghai. Hainan is the region with the best air quality, with an average annual air quality index of 36.7. This is highly related to Hainan's tertiary industry-based economic structure and good climate conditions. In addition, provinces with energy efficiency above the national average include Beijing, Tianjin, Chongqing, Guizhou, Yunnan, Gansu, and Ningxia. Beijing, Tianjin and Shanghai are the key areas of air pollution, but these areas are rich in educational resources and relatively high economic income. They are provinces with a higher level of social welfare, which, to a certain extent, offset the damage caused by air pollution, and thus have a higher energy efficiency.

The provinces with the lowest energy efficiency include Shandong, Hebei, Shanxi, Henan, and Inner Mongolia, whose energy efficiency is below 0.6. In 2016, Hebei and Henan provinces had the worst air quality in China, with an average annual air quality index of 108.7. Almost all the 
10 cities with the worst air quality in China are concentrated in Henan, Hebei, and Shanxi. This is because these areas are rich in coal resources, and coal is the energy source with the highest emission coefficient. The economic structure dominated by energy-intensive industries also determines the higher level of pollutant emissions in these provinces. These provinces should be taken as key areas to formulate energy-saving and emission reduction policies. From the above analysis, we can see that the differences in energy efficiency among provinces are determined by many factors. These factors mainly include the economic development level, social welfare level, air quality, industrial structure, energy consumption structure, climate conditions, and so on.

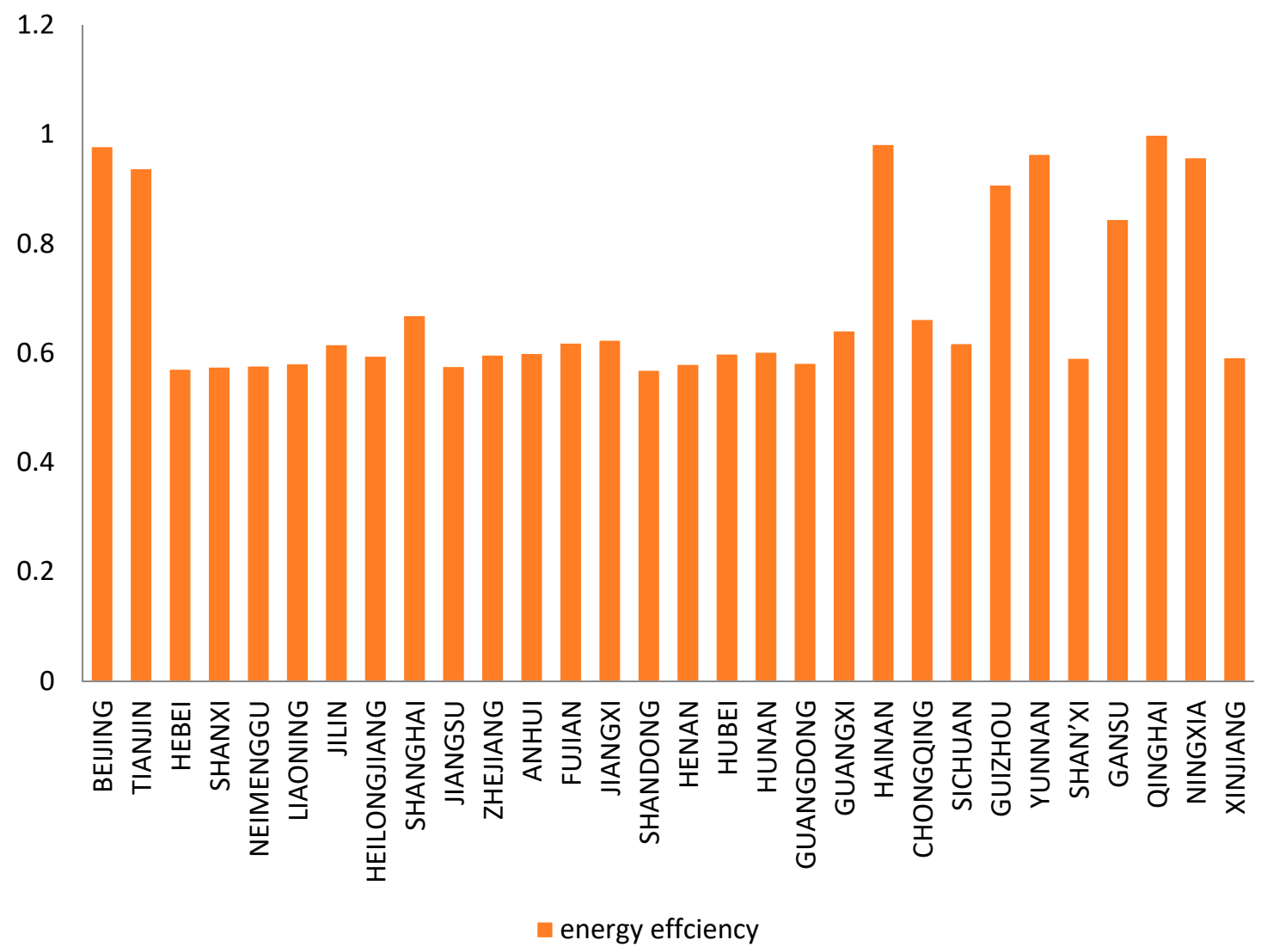

Figure 3. Efficiency scores in each province from 2012 to 2016.

\subsection{Efficency Scores of Eastern, Central, and Western Area}

It is remarkable that the provinces in western areas like Chongqing, Guizhou, Yunnan, Gansu, and Ningxia have an excellent performance in terms of the energy efficiency. This result is obviously different from the previous studies. Previous studies have mostly taken GDP as the output. It is considered that the energy efficiency of eastern areas such as Jiangsu, Zhejiang, and Guangzhou is higher, while that of western areas is lower $[32,33]$. For further discussion, we divided the 30 provinces into three groups, depending on the classifications of Chinese regions: eastern area, central area, and western area. The eastern area is composed of 11 regions: Beijing, Tianjin, Shanghai, Hebei, Shandong, Jiangsu, Zhejiang, and Guangdong. The central area is composed of the eight in land provinces, including Heilongjiang, Jilin, Jiangxi, Shanxi, Anhui, Hunan, Hubei, and Henan. The western area includes 11 provinces: Inner Mongolia, Qinghai, Xinjiang, Chongqing, Guizhou, Yunnan, Shan'xi, Gansu, Ningxia, Guangxi, and Sichuan. We calculated the energy efficiency of the three areas (Table 4 and Figure 4), and found that, during 2012 to 2016, the average efficiency score of the western area was 0.760 , which is higher than that of the eastern area, with a value of 0.697 . The central area displays the worst performance in energy efficiency, with a value of only 0.599 . 
Table 4. Scores in three areas from 2012 to 2016.

\begin{tabular}{ccccccc}
\hline Area & $\mathbf{2 0 1 2}$ & $\mathbf{2 0 1 3}$ & $\mathbf{2 0 1 4}$ & $\mathbf{2 0 1 5}$ & $\mathbf{2 0 1 6}$ & Average Value \\
\hline eastern area & 0.704 & 0.696 & 0.690 & 0.678 & 0.715 & 0.697 \\
central area & 0.598 & 0.597 & 0.597 & 0.598 & 0.606 & 0.599 \\
western area & 0.785 & 0.740 & 0.729 & 0.746 & 0.796 & 0.760 \\
\hline
\end{tabular}

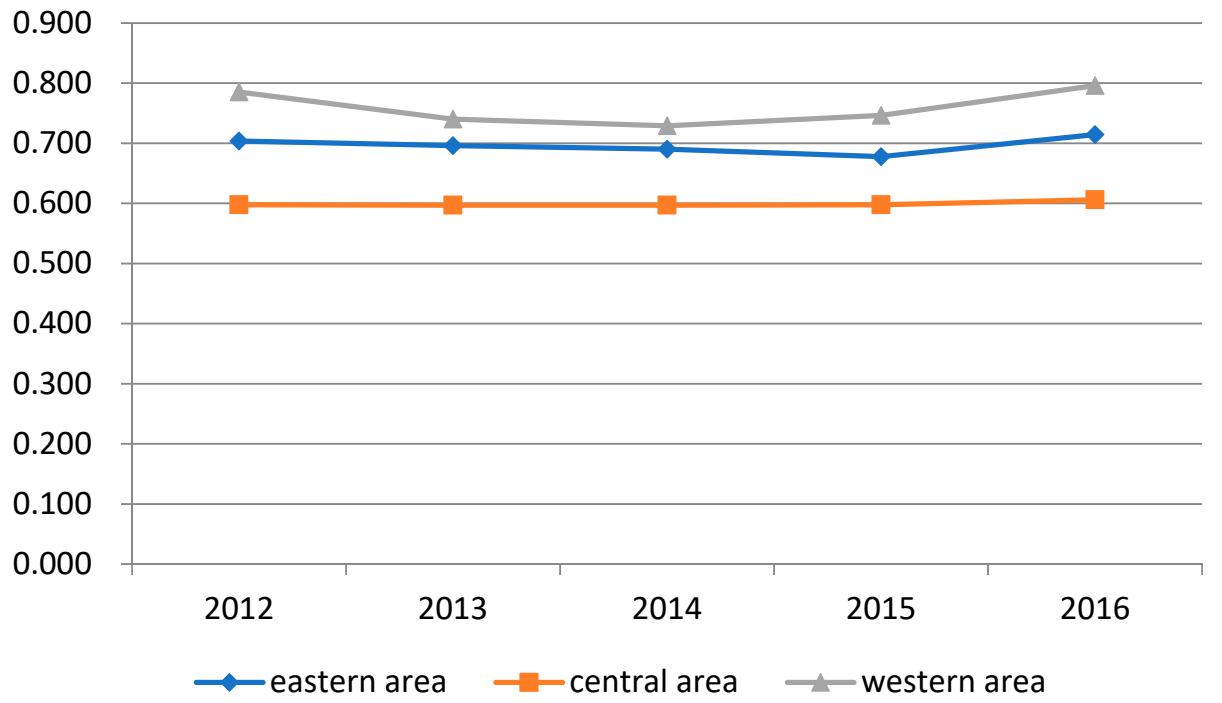

Figure 4. Scores in three areas from 2012 to 2016.

As far as the GDP is concerned, the eastern provinces are naturally higher than the western provinces, but if the output is not GDP but social welfare, the energy efficiency of many western provinces is higher than that of the eastern provinces. This may be because the population of the western region is relatively scarce and the industry is not as developed as that of the eastern region, so the energy consumption and pollutant emissions are relatively small, and people can enjoy a good ecological and natural environment. In the eastern developed provinces, the population density is very high and the living standard is relatively high. A large number of air pollutants are discharged in the production and life, which has a negative impact on people's welfare, thus reducing the energy efficiency. The enlightenment is that in the development of regional economy, we cannot take the growth rate of GDP as the only object, but sacrifice the people's welfare and sustainable development, which is more important.

\section{Energy Saving and Emission Reduction Potential Analysis}

Overall, China's total factor energy efficiency is only 0.64 from the perspective of social welfare, with a large loss of efficiency and a large potential for energy-saving and emission reduction. The energy-saving potential (ESP) for province $i$ at time $t$ could be defined as

$$
\operatorname{ESP}(i, t)=\frac{\text { Actual Energy Input }(i, t)-\text { Target Energy Input }(i, t)}{\text { Actual Energy Input }(i, t)}
$$

Similarly, the emission reduction potential(ERP) for province $i$ at time $t$ could be defined as

$$
\operatorname{ERP}(i, t)=\frac{\text { Actual Emission }(i, t)-\text { Target Emission }(i, t)}{\text { Actual Emission }(i, t)}
$$

Table 5 shows the result of calculating the energy-saving and emission reduction potential of the provinces in 2012-2016. 
Table 5. Emission reduction potential of China's provinces in 2012-2016.

\begin{tabular}{|c|c|c|c|c|c|}
\hline \multirow{2}{*}{ Province } & \multirow{2}{*}{ Energy-Saving Potential } & \multicolumn{4}{|c|}{ Emission Reduction Potential } \\
\hline & & $\mathrm{CO}_{2}$ & $\mathrm{SO}_{2}$ & $\mathrm{NO}_{\mathrm{X}}$ & Dust \\
\hline BEIJING & 0.014 & 0.031 & 0.143 & 0.000 & 0.087 \\
\hline TIANJIN & 0.023 & 0.087 & 0.155 & 0.000 & 0.161 \\
\hline HEBEI & 0.930 & 0.939 & 0.964 & 0.932 & 0.970 \\
\hline SHANXI & 0.898 & 0.925 & 0.975 & 0.905 & 0.974 \\
\hline INNER MOGNOLIA & 0.845 & 0.922 & 0.975 & 0.892 & 0.972 \\
\hline LIAONING & 0.833 & 0.905 & 0.970 & 0.884 & 0.969 \\
\hline JILIN & 0.691 & 0.778 & 0.906 & 0.741 & 0.933 \\
\hline HEILONGJIANG & 0.828 & 0.849 & 0.931 & 0.842 & 0.970 \\
\hline SHANGHAI & 0.475 & 0.704 & 0.786 & 0.455 & 0.675 \\
\hline JIANGSU & 0.869 & 0.918 & 0.964 & 0.916 & 0.954 \\
\hline ZHEJIANG & 0.801 & 0.849 & 0.939 & 0.802 & 0.909 \\
\hline ANHUI & 0.775 & 0.852 & 0.840 & 0.818 & 0.839 \\
\hline FUJIAN & 0.782 & 0.768 & 0.911 & 0.737 & 0.925 \\
\hline JIANGXI & 0.664 & 0.754 & 0.828 & 0.768 & 0.758 \\
\hline SHANDONG & 0.921 & 0.949 & 0.984 & 0.944 & 0.974 \\
\hline HENAN & 0.897 & 0.911 & 0.933 & 0.887 & 0.905 \\
\hline HUBEI & 0.863 & 0.838 & 0.946 & 0.818 & 0.945 \\
\hline HUNAN & 0.865 & 0.826 & 0.923 & 0.814 & 0.878 \\
\hline GUANGDONG & 0.897 & 0.899 & 0.949 & 0.895 & 0.935 \\
\hline GUANGXI & 0.656 & 0.718 & 0.771 & 0.736 & 0.700 \\
\hline HAINAN & 0.001 & 0.024 & 0.066 & 0.000 & 0.052 \\
\hline CHONGQING & 0.779 & 0.638 & 0.933 & 0.606 & 0.885 \\
\hline SICHUAN & 0.847 & 0.784 & 0.878 & 0.717 & 0.774 \\
\hline GUIZHOU & 0.076 & 0.162 & 0.280 & 0.000 & 0.187 \\
\hline YUNNAN & 0.031 & 0.053 & 0.057 & 0.000 & 0.110 \\
\hline SHAN'XI & 0.808 & 0.873 & 0.960 & 0.833 & 0.957 \\
\hline GANSU & 0.219 & 0.368 & 0.436 & 0.000 & 0.255 \\
\hline QINGHAI & 0.004 & 0.002 & 0.002 & 0.000 & 0.030 \\
\hline NINGXIA & 0.054 & 0.074 & 0.071 & 0.000 & 0.060 \\
\hline XINJIANG & 0.807 & 0.872 & 0.889 & 0.816 & 0.861 \\
\hline whole country & 0.605 & 0.642 & 0.712 & 0.592 & 0.687 \\
\hline
\end{tabular}

On the whole, the energy-saving potential is $60.5 \%$. That is to say, if the energy efficiency of all provinces can reach the frontier, the whole country can save more than half of the energy. Among them, the energy-saving potential of Hebei, Shanxi, Shandong, Henan, and other provinces is close to or even more than $90 \%$. From the perspective of emission reduction potential, $\mathrm{SO}_{2}$ has the greatest emission reduction potential, followed by dust and $\mathrm{CO}_{2}$. The provinces with more than $90 \% \mathrm{CO}_{2}$ emission reduction potential include Hebei, Shanxi, Inner Mongolia, Liaoning, Jiangsu, Shandong, and Henan, and the overall national $\mathrm{CO}_{2}$ emission reduction potential is $64.2 \%$. In terms of $\mathrm{SO}_{2}$ emission reduction potential, except for Beijing, Tianjin, Hainan, Yunnan, Qinghai, and Ningxia, the provinces have relatively large emission reduction potential, and the overall $\mathrm{SO}_{2}$ emission reduction potential of the whole country is $71.2 \%$. Furthermore, there are many provinces whose dust emission reduction potential exceeds $90 \%$, mainly concentrated in the northeast and central regions, with the overall dust emission reduction potential of $68.7 \%$. In terms of $\mathrm{NO}_{\mathrm{X}}$ emission reduction, Hebei, Shanxi, Jiangsu, and Shandong have the greatest emission reduction potential, all of which have values above 90\%, while Beijing, Tianjin, Hainan, Guizhou, Yunnan, Gansu, Qinghai, and Ningxia have the best performance in terms of $\mathrm{NO}_{x}$ emission, and the emission potential is 0 . Generally speaking, the four provinces with high emission reduction potential are Hebei, Shanxi, Jiangsu, Shandong, and Henan, which is consistent with the results of the energy efficiency measurement. 


\section{Conclusions and Implications}

From the perspective of social welfare, this paper has used panel data of China's provinces from 2012 to 2016, considering the radial and non-radial characteristics of different input and output indicators and the inseparability between the energy input and non-desired output. It has constructed a non-separable hybrid DEA model, calculated the total factor energy efficiency of China's provinces, and further calculated the energy-saving and emission reduction potential. The main conclusions are as follows:

(1) This paper takes capital, human capital, and energy consumption as the inputs, and social welfare as the desired output, which better reflects the requirements and orientation of sustainable development. Additionally, it takes $\mathrm{CO}_{2}, \mathrm{SO}_{2}, \mathrm{NO}_{X}$, and dust as the non-desired outputs, fully considers the inseparability between the energy input and non-desired output, and is more fit in the actual production process. The results show that the average total factor energy efficiency of China in 2012-2016 was0.694, which means that there was still 30.6\% energy efficiency loss, saving energy consumption, reducing pollutant emissions, and increasing the output of social welfare;

(2) There are great differences in the total factor energy efficiency among provinces. The provinces with the highest energy efficiency are Hainan and Qinghai. It is noteworthy that the provinces in the western area, like Chongqing, Guizhou, Yunnan, Gansu, and Ningxia, exhibit an excellent performance in terms of energy efficiency. During 2012 to 2016, the average efficiency score of the western area was higher than that of the eastern area. The central area had the worst performance in terms of energy efficiency. This result is obviously different from previous energy efficiency estimates based on GDP. Meng Qingchun suggests that energy efficiency among provinces is significantly different. Energy efficiency in the eastern area of China is the highest, followed by central China, and western China is the worst [27]. Ning Zhang et al., found that after 2005, the eastern area had the highest energy efficiency, followed by the western area, and the central area showed the lowest energy efficiency [32].

The implication is that in the development of a regional economy, we cannot take the growth rate of GDP as the only object, but sacrifice social welfare and sustainable development, which is more important. The provinces with the lowest energy efficiency include Shandong, Hebei, Shanxi, Henan, and Inner Mongolia, which should be taken as key areas to formulate energy saving and emission reduction policies;

(3) Overall, the energy-saving potential is $60.5 \%$. That is to say, if the energy efficiency of all provinces can reach the frontier, the whole country can save more than half of the energy. From the perspective of emission reduction potential, $\mathrm{SO}_{2}$ is $71.2 \%$, followed by dust and $\mathrm{CO}_{2}$, which is $68.7 \%$ and $64.2 \%$ respectively, and $\mathrm{NO}_{X}$ is $59.2 \%$, with the smallest potential. The four provinces with high emission reduction potential are Hebei, Shanxi, Jiangsu, Shandong, and Henan.

These conclusions provide some implications for us to formulate relevant policies and suggestions. First, in the process of regional economic development, we should not blindly aim at the growth rate of GDP at the expense of more important social welfare and sustainable development. In recent years, China's economic growth has slowed down and entered a "new normal" period, and pays more attention to the quality of growth and the social welfare. Therefore, when developing energy efficiency policies, we should change the policy orientation and give more consideration to the impact of energy efficiency improvement on improving social welfare and regional sustainable development. Second, the policy development of energy-saving and emission reduction should be based on the characteristics of different regions and provinces. According to the results of this paper, there are great differences in energy efficiency and energy saving and emission reduction potential among provinces. For some key regions, such as Shandong, Hebei, Shanxi, Henan, and Inner Mongolia, the government should increase financial support and reduce the air pollutant emissions by optimizing the energy structure and industrial structure.

It should be pointed out that, in this study, the energy inputs considered come from the burning of fossil fuels, and renewable energy is not included. With the increasing proportion of renewable energy in total energy consumption, it would be more realistic to consider renewable energy in the 
calculation of energy efficiency. Further research may be carried out by considering renewable energy consumption. Given data availability, this study could also be expanded by using the data over a longer time period.

Author Contributions: Conceptualization, H.C. and R.F.; methodology, H.C. and R.F.; software, H.C.; validation, H.C.; formal analysis, H.C. and R.F.; data curation, H.C.; writing-original draft preparation, H.C. and R.F.; writing - review and editing, H.C. and R.F.; visualization, H.C.

Funding: This work was supported in part by the National Social Science Fund of China under Grant No. 14ZDA062, in part by the Henan Philosophy and Social Sciences Planning Project of China under Grant 2016BJJ064, in part by the Henan Provincial Government Decision-making Bidding Project under Grant 2017B100, in part by the Henan University Philosophy and Social Sciences Innovation Team Building Program under grant 2019-CXTD-10, and in part by the Key Research Institute of Humanities and Social Sciences at Universities of Henan.

Conflicts of Interest: The authors declare no conflict of interest.

\section{References}

1. Daly, H.E.; Farley, J. Ecological Economics: Principles and Applications, 2nd ed.; China Renmin University Press: Beijing, China, 2013.

2. IEA. World Energy Outlook 2018. Available online: https://webstore.iea.org/world-energy-outlook-2018 (accessed on 13 November 2018).

3. Pan, J. From ecological imbalance to ecological civilization: The process and Prospect of China's green transformation development in the past 40 years of reform and opening up. Urban Environ. Stud. 2018, $4,3-16$.

4. Lamb, W.F.; Steinberger, J.K.; Bows-Larkin, A.; Peters, G.P.; Roberts, J.T.; Wood, F.R. Transitions in pathways of human development and carbon emissions. Environ. Res. Lett. 2014, 9, 1-14. [CrossRef]

5. Hu, J.L.; Wang, S.C. Total-factor energy efficiency of regions in China. Energy Policy 2006, 34, 3206-3217. [CrossRef]

6. Lin, B.Q.; Du, K.R. The effect of factor market distortions on energy efficiency. Econ. Res. 2013, 9, 125-136.

7. Si, D.; Zhu, T. Review on the Theory and Policy of Energy Economics. Available online: http://www.zxhsd. com/kgsm/ts/2013/06/05/2564013.shtml (accessed on 29 July 2019).

8. Ning, Z.; Yongrok, C. Environmental energy efficiency of China's regional economies: A non-oriented slacks-based measure analysis. Soc. Sci. J. 2013, 50, 225-234.

9. $\mathrm{Li}, \mathrm{K}$.; Lin, B.Q. Metafroniter energy efficiency with $\mathrm{CO}_{2}$ emissions and its convergence analysis for China. Energy Econ. 2015, 48, 230-241. [CrossRef]

10. Wang, K.; Yu, S.W.; Zhang, W. China's regional energy and environmental efficiency: A DEA window analysis based dynamic evaluation. Math. Comput. Mod. 2013, 58, 1117-1127. [CrossRef]

11. Liu, G.P. Research on Energy Welfare Performance and Factor Decomposition in China: Based on G20 Data. Explor. Econ. Issues 2017, 1, 24-30.

12. Scheel, H. Undesirable outputs in efficiency valuations. Eur. J. Oper. Res. 2001, 132, 400-410. [CrossRef]

13. Zhou, P.; Ang, B.W. Linear programming models for measuring economy-wide energy efficiency performance. Energy Policy 2008, 36, 2911-2916. [CrossRef]

14. Shen, N.; Wang, Q. Spatial Model of Energy Efficiency and Differential Energy Saving Path in China: Analysis Based on DEA Three-stage Model. Syst. Sci. Math. 2013, 33, 457-467.

15. Apergis, N.; Aye, G.C.; Barros, C.P.; Gupta, R.; Wanke, P. Energy efficiency of selected OECD countries: A slacks based model with undesirable outputs. Energy Econ. 2015, 51, 45-53. [CrossRef]

16. Wang, B.; Yang, Y.; Lai, P.; Yu, L. Study on Energy Efficiency and Energy Conservation and Emission Reduction Potential of China Regions Considering Natural Environmental Differences. Ind. Rev. 2016, 7, 82-100.

17. Wang, T.T.; Zhu, J.P. Energy Efficiency of Electric Power Industry under Environmental Constraints. China Popul. Resour. Environ. 2015, 25, 120-127. [CrossRef] [PubMed]

18. Li, L.B.; Hu, J.L. Ecological total-factor energy efficiency of regions in China. Energy Policy 2012, 46, 216-224. [CrossRef]

19. Li, L.B. Dynamic Evolution of China's Energy Performance, Regional Gap and Cause Identification. Manag. World 2015, 11, 40-52. 
20. Liao, H.; Wei, Y.M. Recognition of Energy Efficiency and Its Relationship with Economic System. J. Public Manag. 2010, 7, 28-34.

21. Mazur, A. Does increasing energy or electricity consumption improve quality of life in industrial nations? Energy Policy 2011, 39, 2568-2572. [CrossRef]

22. Sweidan, O.D.; Alwaked, A. Economic development and the energy intensity of human well-being: Evidence from the GCC countries. Renew. Sustain. Energy Rev. 2016, 55, 1363-1369. [CrossRef]

23. Angeliki, N.; Can, T. Energy consumption and Sustainable Economic Welfare in G7 countries: A comparison with the conventional nexus. Renew. Sustain. Energy Rev. 2017, 69, 892-901.

24. Angeliki, N.; Antonio, C.; Jose, A. Redefining the energy-growth nexus with an index for sustainable economic welfare in Europe. Energy 2017, 141, 1254-1268.

25. Charnes, A.; Cooper, W.W.; Rhodes, E. Measuring the efficiency of decision making units. Eur. J. Oper. Res. 1978, 2, 429-444. [CrossRef]

26. Tone, K.; Tsutsui, M. Applying an Efficiency Measure of Desirable and Undesirable Outputs in DEA to U.S. Electric Utilities. Soc. Sci. Electron. Publ. 2011, 4, 236-249. [CrossRef]

27. Meng, Q.C.; Huang, W.D.; Rong, X.X. Energy Efficiency Measurement and Energy Conservation and Emission Reduction Potential Analysis in Haze Environment-NH-DEA Model Based on Multi-Undesired Output. China Manag. Sci. 2016, 24, 53-61.

28. He, K.B. Seven questions for fog and haze: When can we breathe clean air? Available online: http: //www.xinhuanet.com/fortune/2017-01/07/c_1120262575.htm (accessed on 28 July 2019).

29. Zhang, J.; Wu, G.Y.; Zhang, J.P. Estimation of Interprovincial Material Capital Stock in China: 1952-2000. Econ. Res. 2004, 10, 35-44.

30. United Nations Development Programme. Human Development Report 2015: Work for Human Development; United Nations Development Programme: New York, NY, USA, 2015.

31. IPCC. 2006 IPCC Guidelines for National Greenhouse Gas Inventories; IPCC: Paris, France, 2006.

32. Zhang, N.; Kong, F.B.; Yu, Y.N. Measuring ecological total-factor energy efficiency incorporating regional heterogeneities in China. Ecol. Indic. 2015, 51, 165-172. [CrossRef]

33. Li, Y.; Chiu, Y.; Lin, T.Y. Energy and Environmental Efficiency in Different Chinese Regions. Sustainability 2019, 11, 1216. [CrossRef]

(C) 2019 by the authors. Licensee MDPI, Basel, Switzerland. This article is an open access article distributed under the terms and conditions of the Creative Commons Attribution (CC BY) license (http://creativecommons.org/licenses/by/4.0/). 